\title{
Temas da Agenda de Segurança Hemisférica: percepções do Congresso dos Estados Unidos
}

\author{
Themes of the Hemispheric Security Agenda: \\ perceptions of the United States Congress
}

Juliana Viggiano*

\section{Resumo}

Esse artigo tem por objetivo apresentar como o Congresso dos Estados Unidos definiu, em temas e termos, a agenda de segurança para a América Latina entre 1993 e 2004. Pretende-se oferecer subsídios para melhor se compreender a aparentemente incompativel relação, identificada no processo de construção-implementação da agenda, entre uma percepção complexa das causas dos fenômenos de (in) segurança na região e a posição privilegiada assumida pelas alternativas político-militares tradicionais no seu trato. A análise aponta que a agenda de segurança hemisférica é composta pelos seguintes temas, de acordo com o Congresso: tráfico de drogas, ajuda externa, imigração, direitos humanos e democracia.

Palavras-chave: segurança internacional; relação Estados Unidos-América Latina; agenda de segurança, agenda hemisférica.

\section{Abstract}

This paper examines what themes and terms have defined the hemispheric security agenda according to the United States Congress comprising the years 1993 to 2004. It intends to offer subsidies to better understanding the seemingly incompatible relationship, identified in the process of constructing and implementing the hemispheric security agenda, between a complex perception of the causes of (in) security phenomena in the region and the preferred option for traditional political-military alternative in dealing with such issues. This paper shows Congress considers the following subjects as relevant to the hemispheric security agenda: drug trade, foreign aid, immigration, human rights and democracy.

Keywords: international security; United States-Latin America relations; security agenda, hemispheric agenda.

\footnotetext{
* Professora do Departamento de Economia e Relações Internacionais da Universidade Federal de Santa Catarina. E-mail: juliana. viggiano@gmail.com.
} 


\section{Introdução}

Esse artigo tem por propósito apresentar os temas que compõem a agenda de segurança dos Estados Unidos para a América Latina segundo a percepção do Congresso. Tal trabalho possui como pano de fundo o reconhecimento de uma discrepância entre a implementação de políticas de segurança ainda muito dependentes dos instrumentos tradicionais e a narrativa da ameaça, que assume caráter de interdependência.

Com respeito à última observação, às questões pontuais e mais específicas com relação à segurança que absorveram a atenção dos formuladores de política externa nos Estados Unidos, somam-se duas vertentes complementares que compõem a agenda hemisférica: a) manutenção e estabilidade dos regimes democráticos nos países da região e b) comércio.

O conteúdo da agenda de segurança hemisférica formulada pelos Estados Unidos contempla um conjunto de ameaças de natureza transnacional e identifica com clareza a crescente interdependência entre os países do hemisfério em todos os diversos campos de atuação, atenuando progressivamente a fronteira entre os assuntos domésticos e internacionais. O documento intitulado A National Security Strategy for a New Century, elaborado em 1999 pelo Departamento de Estado, apresenta a questão da seguinte forma: "As principais preocupações de segurança no hemisfério são de natureza transnacional, tais como tráfico de drogas, crime organizado, lavagem de dinheiro, imigração ilegal, tráfico de armas de fogo e terrorismo"1.

A racionalidade que confere coerência a essa agenda de segurança hemisférica ampliada depende justamente da impossibilidade de se olhar os fenômenos particulares de segurança selecionados pelo governo norte-americano dissociados do caráter interdependente que apresentam com outros temas não por excelência posicionados na agenda de segurança, como democracia, direitos humanos e imigração, associados à perspectiva da estabilidade política. 0 ponto fundamental consiste em reconhecer o acentuado grau em que se encontram imbricadas as relações sociais, econômicas e políticas entre as nações e sociedades do hemisfério. Portanto, a fonte dos problemas se localiza nos países hemisféricos, mas suas implicações assumem status de problemas de segurança nacional pela administração norte-americana. A intrincada interdependência, por assim, dizer, nesses dois níveis (geográfico e temático), permite identificar a dinâmica que se estabelece na definição e sustentação da agenda de segurança dos Estados Unidos para a região.

De acordo com Villa (2006, p. 1), "[a] racionalidade da resposta (aos problemas colocados pela agenda hemisférica) parece ter seguido um padrão bastante institucionalista de acordo com a qual a interdependência que estes temas apresentam com outros como pobreza, instabilidade política e baixo desenvolvimento podem ter respostas geradas e veiculadas em instituições". Apesar da abordagem interdependentista e institucionalista que assume o discurso do governo

\footnotetext{
1 A preocupação norte-americana com essas questões enumeradas não assume a mesma intensidade indiscriminadamente em todos os países da região aqui tratada. Geograficamente, os principais pontos de atenção dispensados pelo governo se destinam à América Central, à região andina e, sobretudo, no período imediatamente posterior aos ataques terroristas de 11 de setembro de 2001, à região da tríplice fronteira entre Brasil, Argentina e Paraguai. Assim, só no período 1994-1996, a Bolívia, a Colômbia e o Peru consumiram entre $88 \%$ e $91 \%$ do orçamento internacional antidrogas dos EUA (VILLA, 2006, p. 22).
} 
norte-americano na construção de sua agenda, estabelecendo dependência entre estabilidade político-institucional democrática e segurança, um levantamento panorâmico de diversas iniciativas dos Estados Unidos na e para a região, revela o papel privilegiado que os instrumentos tradicionais de combate à segurança ocuparam nos anos 1990 e início dos anos 2000. Revela, em outras palavras, o viés militarizado que assumiu a aproximação entre os governos dos Estados Unidos e dos demais países do continente na tentativa de erradicar aqueles que foram identificados como os principais problemas de segurança da região.

Quando se analisa mais cuidadosamente os documentos e relatórios elaborados pelas diversas agências governamentais dos Estados Unidos, as alternativas militares, embora não descartadas, ocupam um papel de complementaridade a uma estratégia de ação mais abrangente. Da mesma maneira, os pontos específicos que permeiam a agenda de segurança surgem constantemente como uma consequência nefasta da incapacidade dos governos da região em atender às necessidades da sua população, gerando uma situação de insatisfação permanente.

Por que, então, as iniciativas predominantes de longo prazo e que absorvem grande parte dos recursos alocados para o hemisfério na estratégia de atuação dos Estados Unidos na região assumiram caráter militar? Por que apesar do reconhecimento por parte das elites decisórias da interdependência entre as unidades políticas do continente e da interconexão complexa entre estabilidade democrática, segurança e comércio, as estratégias de parceria na região hemisférica apóiam-se com maior peso em instrumentos aparentemente anacrônicos? Por que, a despeito do reconhecimento por parte dos atores políticos sobre a conexão entre as questões de segurança e de estabilidade política dos regimes democráticos na região, a dimensão política não ocupa papel prioritário nas iniciativas do governo dos Estados Unidos? Um caminho promissor para tentar dar respostas a essas indagações e, portanto, identificar por que certo conjunto de alternativas se destaca frente a outros, surge com os trabalhos que se dedicam a estudar a definição da agenda do governo. O que está em jogo nessa proposta é compreender as particularidades do processo político no qual estão envolvidos os atores responsáveis pela definição da agenda de segurança hemisférica dominada pelo viés militar.

Segundo Kingdom (1995), agenda é definida como a "lista de temas ou problemas aos quais membros do governo e pessoas fora do governo intimamente associadas a esses membros estejam prestando muita atenção em qualquer momento". (KINGDOM, 1995:3). Duas questões básicas norteiam aqueles dedicados a desvendar os mecanismos que lapidam a agenda política: como surgem os assuntos públicos e por que alguns (e não outros) ascendem à arena pública; e quais atores participam do processo de definição dos assuntos públicos (KINCDOM, 1995, FUKS, 2001). A agenda se apresenta como uma proposta volátil e flexível, que se altera de acordo com a modificação dos atores envolvidos em sua formulação e o rearranjo na relação de forças entre os mesmos. Não somente os temas a serem considerados são objeto dos estudos de definição de agenda, mas também o conjunto de alternativas contempladas pelos formuladores de política para sua implementação (KINCDOM, 1995).

Nos Estados Unidos, a permeabilidade do sistema democrático permite o acesso de uma pluralidade de atores à arena política, representantes de diversas camadas e grupos da sociedade. A compreensão mais detalhada da agenda política, no caso, da agenda de segurança 
hemisférica, requer a identificação de quais atores efetivamente moldam seu conteúdo. Alcançar esse objetivo requer compreender o mecanismo de interação entre os grupos e indivíduos que participam desse processo, dinâmica esta que vai além da dimensão puramente institucional. Qualquer estudo dessa natureza, portanto, constitui-se de uma ampla rede de informações e um sistema complexo de interações.

O presente artigo é uma tentativa inicial de se pensar esse processo a partir do conjunto de ideias e alternativas levantadas sobre as principais questões de segurança hemisférica por parte de um ator específico: o Congresso dos Estados Unidos. Se pontuar a origem das ideias e alternativas aventadas no âmbito do Congresso não se configura recurso suficiente para se identificar as particularidades dos conflitos e interações políticas que culminam, em última instância, no que se denomina agenda, sem dúvida é um ponto de partida para começar a se compreender esse processo?2.

Embora as duas casas legislativas possuam comitês específicos para tratar das questões externas - Comitê de Relações Exteriores ${ }^{3}$ do Senado e o Comitê de Relações Internacionais ${ }^{4}$ da Câmara, anteriormente chamado Comitê de Assuntos Exteriores ${ }^{5}$ - outros seis comitês também participam das decisões relativas à política externa: Comitês de Serviços Armados, Dotações e Inteligência ${ }^{6}$ de cada uma das instâncias do Congresso. Todas essas unidades reivindicam jurisdição sobre a formulação de política externa. O presente artigo centra atenção nos dois comitês específicos, ou seja, o Comitê de Relações Exteriores do Senado e o Comitê de Relações Internacionais da Câmara, e em seus subcomitês que tratam das questões hemisféricas, os quais se subdividem em Subcomitê para Assuntos do Hemisfério Ocidental e do Corpo da Paz’ e o Subcomitê de Assuntos do Hemisfério Ocidental ${ }^{8}$, respectivamente. No Senado, ainda se leva em consideração as informações referentes ao Subcomitê para Terrorismo, Narcóticos e Operações Internacionais ${ }^{9}$, dada a primazia do problema do tráfico para a agenda.

A escolha em trabalhar exclusivamente com esses dois comitês e seus subcomitês relacionados decorre do propósito de apresentar quais e como as questões de segurança são delimitadas pelo Congresso, pois são nesses espaços que os congressistas expõem com mais frequência suas visões sobre os temas que compõem essa agenda. Portanto, as menções ao congresso e aos congressistas devem ser lidas acompanhadas dessa limitação.

0 trabalho se divide em três partes. A primeira parte dedica-se a expor a relevância do Congresso para a formulação de política externa e as dificuldades particulares de se estudar esse ator. Em seguida, apresenta-se o posicionamento do Congresso frente às questões que permeiam a agenda de segurança hemisférica dos Estados Unidos: ajuda externa, imigração,

\footnotetext{
2 A preocupação com a origem, em realidade, traça o quadro em que se insere o debate. Não é propriamente a fonte de origem das ideias que importa, mas sim a receptividade do governo para incorporar determinadas ideias.

3 Em inglês, Committee on Foreign Relations.

4 Em inglês, Committee on International Relations.

5 Em inglês, Committee on Foreign Affairs.

6 Em inglês, Armed Services, Appropriations e Intelligence respectivamente.

7 Em inglês, Subcommitte on Western Hemisphere and Peace Corps Affairs. O Corpo da Paz é uma organização financiada pelo governo dos Estados Unidos que desenvolve trabalho voluntário em países em desenvolvimento.

8 Em inglês, Subcommittee on Western Hemisphere Affairs.

9 Em inglês, Subcommitte on Terrorism, Narcotics and International Operations.
} 
direitos humanos, democracia e tráfico de drogas, esse último apresentado em tópico separado dada sua proeminência. A discussão abarca do $103^{\circ}$ ao $108^{\circ}$ Congresso, englobando os anos de 1993 a 2004. Foca-se, portanto, no período inicial do pós-Guerra Fria até a legislatura imediatamente posterior ao 11 de setembro, permitindo, dessa forma, avaliar o impacto desse evento sobre a agenda.

\section{Papel do Congresso na política externa}

Muito já se discutiu na literatura sobre a importância do Congresso norte-americano na definição da política externa. Com maior ou menor ênfase, aceita-se que o poder legislativo detém algum tipo de influência.

O mainstream da área, embora conferisse ao Congresso maior influência na formulação de política externa nos anos posteriores à década de 1970, ainda creditava ao Executivo considerável flexibilidade na sua definição. Nos anos de 1990, contudo, alguns trabalhos que hoje são referência no estudo da política externa atribuem papel de relevância ao Congresso (LIDSAY e RIPLEY, 1992, LOHMANN e O`HALLORAN, 1994, MILNER, 1997, MARTIN, 2001)10.

Embora não se refira especificamente à formulação de política externa, Kingdom afirma que suas pesquisas não deixam margem de dúvida sobre o papel fundamental que cumpre o Congresso na definição de agenda:

One comes to a consideration of the place of Congress in agenda setting with mixed expectations. ... Congress may produce 535 individual agendas incapable of coordination, may lack control over implementation, may have deficiencies in the expertise necessary to draft detailed proposals, and may be at the mercy of interest groups, constituencies, and administration pressure that pull them hither and yon, preventing them from setting an agenda on their own. No such ambiguity exists in the quatitative indicators drawn from my interviews. Respondents judge members of Congress to be important in 91 percent of the interviews, which places them right next to the administration and well ahead of any of the individual components of the administration. Hill members are coded very important in 13 of the 23 case studies, and somewhat important in the remaining 10. Again, these figures are far ahead of those of any other actor, and suggest strongly the central importance of senators and representatives. (KINGDOM, 1995: 34).

Em particular, a formulação da política externa apresenta certa ambiguidade quando considerada pelo ângulo institucional, característica que instigou inicialmente a controvérsia na bibliografia sobre a importância de cada um dos poderes. Ou seja, a quem compete, juridicamente, as decisões sobre os encaminhamentos da política internacional? A resposta para tal pergunta não é consensual uma vez que a Constituição dos Estados Unidos, responsável por delegar as competências do Executivo e do Legislativo no sistema de governo, deixa margem para interpretações (HARDY, 1995, MILNER, 1997).

10 Vale salientar que esses autores se inserem na tradição racionalista: preocupam-se com a interação estratégica e focam suas pesquisas nos outcomes e não nos processos. 
No entanto, o Congresso desfruta de três prerrogativas constitucionais específicas que asseguram sua participação, direta ou indireta, na formulação de política externa: autoridade sobre tratados comerciais, a necessidade da aprovação por dois terços do Senado para declarar guerras e a alocação de recursos ${ }^{11}$ (KEGLEY e WITTKOPF, 1996, CAMERON, 2002). Devido à disposição constitucional acerca da alocação de recursos, a função legislativa rotineira mais visível do Congresso (excetuando a declaração de guerras) consiste nas restrições que impõe à administração a respeito das possibilidades de assistência externa (HAHN, 2003).

Além dessas atribuições formais, o Congresso utiliza uma série de caminhos extralegislativos para moldar a opinião dos membros do executivo, de governos de outros países e do público. O Congresso pode organizar discussões informais para aconselhar e fazer consultas com as agências do executivo, representantes dos demais países e outros atores domésticos e internacionais da esfera social e pode convocar encontros formais por meio de audiências (hearings) com esses mesmos atores. O Congresso também tem liberdade para criar fóruns especiais para discussão de temas de seu interesse, produzir pronunciamentos acerca de políticas estabelecidas ou em deliberação, escrever cartas para membros oficiais do seu país ou do exterior, se posicionar por meio da mídia e processar agências do poder executivo, inclusive 0 gabinete presidencial (HAHN, 2003: 49).

Apesar das suas prerrogativas institucionais, a capacidade de influência do Congresso na elaboração da política externa é definida circunstancialmente. Aparentemente, o Congresso toma maior iniciativa com relação à formulação de política externa quando o executivo abre espaço para sua atuação (HARDY, 1995, MILNER, 1997) e nos períodos posteriores a crises e guerras, maneira de se contrapor e contrabalançar a preponderância que em geral assume o Executivo em situações dessa natureza (DEIBEL, 2000). No entanto, é possível identificar alguns padrões históricos e conformações mais específicas do contexto que interferem nas medidas de peso dos atores governamentais na balança decisória.

Em primeiro lugar, como citado acima, a prioridade que a administração atribui a determinado tema pode afetar positiva ou negativamente a possibilidade de influência do poder legislativo na definição da política externa. Hahn (2003) argumenta que o Congresso tem particular impacto em assuntos de baixa prioridade nos quais o presidente não pode e não tem interesse em dispensar capital político para conseguir uma vitória. 0 Congresso, então, é capaz de barganhar com o executivo em termos de concessões, demandando certa atenção para seus interesses específicos.

Os diversos assuntos da agenda de segurança hemisférica tiveram maior ou menor relevância para o executivo ao longo do período aqui considerado. As questões de imigração, por exemplo, tiveram mais visibilidade tanto por parte do Congresso quanto por parte da administração no período compreendido entre 1994 e 199612. A preocupação com o tráfico de drogas permaneceu na agenda com mais constância ao longo do período, embora a administração Clinton tenha adotado uma postura distinta da desejada pelo Congresso nos

11 O Senado ainda é responsável pela aprovação de alguns membros da administração e de todos os representantes norte-americanos no exterior.

12 Considerando especificamente o problema de imigrantes não documentados oriundos de países da América Latina. 
primeiros anos de governo. Os congressistas envolvidos mais diretamente com as questões hemisféricas acreditam que o executivo, nos anos em que foi comandado pelo presidente democrata, não deu a devida atenção às ameaças advindas da região latino-americana. O representante Republicano Dan Burton, membro do Subcommittee on Western Hemisphere do Comitê de Relações Internacionais da Câmara, ao comentar sobre a implementação do Plano Colômbia e o papel dos Estados Unidos nesse processo, faz a seguinte observação: "Minha esperança é que não seja tarde demais para a Colômbia. Pena que somente baixos números nas pesquisas em um ano eleitoral fizeram com que o governo Clinton-Gore se engajasse nesse tema vital de segurança nacional" (CÂMARA DOS DEPUTADOS DOS ESTADOS UNIDOS, 2000e, p. 6).

Convém mencionar, contudo, que a questão hemisférica ocupa segundo plano na agenda do Congresso dos Estados Unidos. Dos 122 decretos e medidas considerados pelo Comitê de Relações Exteriores ${ }^{13}$ do Senado entre janeiro de 1999 e dezembro de 2000, somente cinco referiam-se mais diretamente a problemas relacionados à América Latina: tráfico de substâncias ilegais e corrupção. Nenhuma das cinco medidas foi aprovada pelo comitê.

A segunda observação que afeta a capacidade de interferência do legislativo sobre a política externa diz respeito ao grau de ressonância política dos temas da agenda no âmbito doméstico. Em outras palavras, o interesse dos congressistas pelas questões de política externa é proporcional ao interesse da mídia, da opinião pública ou dos cidadãos de um determinado distrito eleitoral nos assuntos a serem considerados. Questões intermésticas, ou seja, que impactam as arenas doméstica e internacional, também tendem a contribuir para o aumento do grau de interesse dos congressistas pela política externa (HAHN, 2003).

Na realidade, parte da bibliografia especializada em compreender a importância do Capitólio na formulação de política externa atribui à necessidade primária de reeleição, que orienta a atitude dos congressistas, a principal justificativa para seu desinteresse pelos assuntos internacionais (KEGLEY e WITTKOPF, 1996, CAMERON, 2002).

Verifica-se de fato que algumas áreas da política externa recebem maior atenção do que outras de acordo com sua capacidade de mobilização política. Organizações como o Cuban American National Foundation (CANF) e o Committee in Solidarity with the People of El Salvador (CISPE) 14 podem ser bastante efetivas em pressionar os membros do Congresso a atuarem com assertividade frente às questões de seu interesse no plano político.

13 O Subcomitê para Assuntos do Hemisfério Ocidental e do Corpo da Paz, uma subdivisão do próprio Comitê de Relações Exteriores do Senado, realizou, nesse mesmo período, oito painéis de discussão sobre temas relacionados à região hemisférica, o dobro das audiências que organizou ao longo do $103^{\circ}$ Congresso: U.S. Relief Efforts in Response to Hurricane Mitch; Colômbia: The Threat to U.S. Interests and Regional Security; Targeting Assets of Drug Kingpins; The State of Democracy and the Rule of Law in the Americas; Confronting Threats to Security in the Americas; Overview of U.S. Counterterrorism Policy \& President Clinton's Decision to Grant Clemency to FALN Terrorists; Proposed Emergency Anti-Drug Assistance to Colombia e Lessons of NAFTA for U.S. Relations with the Americas. As audiências são encontros organizados pelos subcomitês especializados com membros da administração, acadêmicos, representantes de think tanks e grupos organizados da sociedade civil para se discutir políticas adotadas pelo governo e alternativas para resolução de problemas. São, portanto, uma fonte rica de informações para estudar a formulação de agenda. Para elaboração desse artigo, só se teve acesso aos documentos referentes às audiências realizadas pela Câmara.

14 O CAFN é uma fundação comandada por exilados cubanos que pressionam o governo a adotarem posturas mais rígidas frente ao regime castrista. O CISPE é bastante crítico às políticas adotadas pelo governo norte-americano para El Salvador. Embora adote uma postura crítica no campo da política externa, a organização pronuncia-se majoritariamente sobre medidas domésticas que afetam os interesses dos imigrantes nos Estados Unidos. 
Um dos programas de maior permanência ao longo dos anos, dentre o número reduzido de iniciativas da Agência dos Estados Unidos para o Desenvolvimento Internacional (United States Agency for International Development - USAID) para a região15, consiste em garantir a intensificação e disseminação de informações em Cuba com o intuito de promover a transição do regime, ecoando as preocupações do Congresso. Essa iniciativa da USAID dá continuidade a uma lei aprovada em 1992 pelo presidente Bush, por pressão do Congresso e do posicionamento de Clinton no ano eleitoral:

Conservative leaders from the Cuban-American community, led by the Cuban American National Foundation (CANF), lobbied the US Congress to attempt to bring the regime down by forcing other governments to stop trading with Cuba, as approach introduced by Representative Robert Torricelli via a bill that also included a "track II" provision designed to encourage more communication with Cuba's civil society. Although President Bush had apposed the bill on grounds that it would have an adverse affect upon Canada, among others, he reversed course in the Spring of 1992 when Clinton, in the course of the presidential campaign, endorsed the measure; Bush then signed it. (...) [the] law did succeed in defining US policy toward Cuba for the Clinton administration. (PASTOR, 1996: 111).

No entanto, a despeito do caráter interméstico das questões contempladas pela agenda de segurança hemisférica e do domínio da política paroquialista no Congresso, as ameaças compartilhadas no âmbito doméstico e internacional parecem não terem sido suficientes para mobilizar um número de eleitores significativo a fim de aumentar o interesse dos congressistas a se envolverem com os problemas de segurança no continente, mesmo com a flexibilidade que adquiriram as questões de segurança no pós-Guerra Fria.

Finalmente, os dois últimos cenários de maior participação do Congresso na formulação da política externa referem-se à percepção por parte do Congresso da inabilidade do presidente em lidar de forma adequada com determinadas questões internacionais, e às características individuais dos detentores de cargos administrativos e eletivos que podem definir a interação entre os dois locus de poder: a personalidade do presidente, dos representantes das agências governamentais e dos membros do Congresso (HAHN, 2003).

A insatisfação do $104^{\circ}$. Congresso, composto por uma maioria de representantes republicanos, com a falta de compromisso do governo Clinton com a política da guerra às drogas, isto é, por um lado, a marginalização da questão e, por outro, a percepção de que a administração preferia concentrar-se na demanda e no desenvolvimento de políticas de assistência econômica e social ao invés de buscar a solução do problema do tráfico dando continuidade à abordagem militarizada que assumiu as iniciativas da gestão anterior, certamente foram uma das grandes motivações para a reestruturação da política de ajuda externa que o legislativo realizou em junho de 1995.

\footnotetext{
15 Os programas da USAID visando consolidar o processo democrático na região na década de 1990 consistem em um projeto para aumentar a participação política das mulheres no Haiti e em projetos para construir "Centros de Justiça" integrados direcionados à resolução de conflitos de populações carentes em El Alto. Acessado em http://www.usaid.gov/locations/latin_america_caribbean/ democracy/ - acesso em 11 de novembro de 2013.
} 
A dimensão individual da análise de alguns representantes também parece ser relevante para explicar a postura do Congresso frente às questões de segurança hemisférica, em especial, dos presidentes dos comitês especializados em política externa ${ }^{16}$. Ao selecionar três estudos de caso em que os Estados Unidos prestam assistência externa para países latino-americanos, Hahn (2003) faz o seguinte comentário:

The enactment of the 1993 Helms-Burton ${ }^{17}$ Law, sanctioning countries that do business with Cuba, is a product of two strong Foreign Relations' Committee and Subcommittee chairs. The combination of personal and institutional influence enabled them to toughen the more moderate policy of the Clinton administration towards Cuba. (HAHN, 2003: 53, 54)

Um último aspecto que vale ser mencionado antes de se iniciar a próxima seção do texto refere-se às particularidades do sistema eleitoral norte-americano e suas repercussões no congresso. 0 sistema político dos Estados Unidos é dominado por dois grandes partidos: 0 Partido Republicano e o Partido Democrata18. Autores como Keegley e Wittpkof (1996), Wittkopf e McCormick (1998) e Cameron (2001) afirmam que, com o fim da Guerra Fria, a participação individual dos membros do Congresso passa a ser mais decisiva, embora a disciplina partidária não seja um traço historicamente característico de nenhum dos dois grandes partidos.

No que diz respeito à agenda de segurança hemisférica, no entanto, podemos identificar certo padrão de posicionamento frente às questões, como a ajuda externa e a opção pelo uso da força como instrumento de política externa no combate ao tráfico de drogas. De fato, o conjunto de alternativas vislumbradas pelos representantes Democratas, seja na Câmara ou no Senado, embora não desconsiderem os meios militares como instrumento, sempre advogam em favor da pluralização e do fortalecimento de iniciativas que garantam a manutenção dos regimes democráticos, sua eficiência em atender às demandas das populações e do desenvolvimento da economia, em contraposição aos seus pares filiados ao partido Republicano.

\section{Temas da agenda: Ajuda Externa, Imigração, Direitos Humanos e Democracia}

A alocação de recursos para a ajuda externa, como mencionado na seção anterior, é um dos mecanismos institucionais formais mais eficientes que o Congresso detém para limitar a ação da

16 Embora esse seja um aspecto relevante para mapear o processo de construção da agenda, a proposta do artigo é muito mais simples: posicionar o congresso frente às questões de segurança hemisférica.

17 O Republicano da Carolina do Norte Jesse Helms foi Presidente do Comitê de Relações Exteriores do Senado de 1995 a 2001. Bastante polêmico por suas posições conservadoras radicais, Helms era favorável à escalada da guerra contra as drogas e aprovou, em 1996, uma lei cujo propósito era aumentar a parcela de financiamento dos fundos dedicados à eliminação do tráfico de drogas no orçamento total da ajuda externa.

18 Seguindo os passos da ciência política, alguns estudos de relações internacionais que trabalham com a formulação de política externa nos Estádios Unidos - vale a observação de que a maioria dos estudos teóricos na área de política externa ainda referem-se ao sistema político norte-americano, sobretudo na década anterior, e problematizam o impacto esperado do governo dividido nos outcomes. 0 governo dividido diz respeito aos períodos em que a maioria dos representantes eleitos que ocupam os cargos no poder legislativo pertence ao partido de oposição ao presidente. Em outras palavras, quando o presidente é democrata e a maioria no Congresso é republicana - como foi o caso do governo Clinton a partir de 1995 - ou vice-versa. Esses estudos tratam principalmente de questões comerciais e trabalham dentro da perspectiva teórica da ação estratégica. Lohman e O`Hallaran (1994) afirmam, por exemplo, que o governo dividido tem influência sobre o outcome esperado da política comercial externa a ser adotada pelos Estados Unidos. 
administração e influenciar a formulação de política externa. As determinações de ajuda externa estipuladas pelo Congresso referem-se à distribuição dos recursos disponiveis para a aplicação em todas as esferas - econômica, política, social e militar - nas quais os Estados Unidos atuam nos demais países do mundo. 0 Congresso tem liberdade para alocar os recursos de forma bem específica ou de maneira mais vaga, conferindo menor ou maior mobilidade à administração, respectivamente, na utilização das somas estabelecidas.

O Congresso de maioria republicana que tomou posse em 1995 aprovou, no dia 17 de junho, o Foreign Aid Reduction Act com o propósito de reduzir os gastos com assistência externa oferecidas pelos Estados Unidos para os anos de 1996 e 1997. A lei reduziu significativamente os gastos com a ajuda externa frente às apropriações designadas para o ano de 1995. 0 Ato previu cortes nessa área de US\$2.104 bilhões em comparação com o ano fiscal de 1995 e reduziu em US\$ 2.994 bilhões os recursos destinados à assistência requeridos pelo presidente para o Ano Fiscal de 1996, incluindo a recusa em autorizar a alocação US\$ 1.25 bilhões para a USAID (SENADO DOS ESTADOS UNIDOS, 1995b).

$0104^{\circ}$ Congresso conclui no documento em questão que, analisando historicamente os esforços de assistência prestados pelos Estados Unidos para os países em desenvolvimento, os resultados dos programas de ajuda social e econômica desencorajam a iniciativa individual e, como consequência, o fortalecimento do livre mercado, e constatam que as parcerias bilaterais firmadas para transferência de recursos acabaram por favorecer regimes não democráticos. Esse sistema de ajuda tem ainda o efeito negativo de fomentar a dependência dos países em desenvolvimento para com os Estados Unidos. Citando o exemplo do Haiti, o Ato afirma que a ajuda no sentido mais desenvolvimentista, ao contrário do que defende a USAID, não garante a estabilidade dos regimes democráticos ou sua institucionalização: "O Haiti recebe ajuda externa há 51 anos e, antes disso, os EUA ocuparam o Haiti por 19 anos. Entretanto, o Haiti ainda espera seu primeiro governo eleito democraticamente de verdade" (SENADO DOS ESTADOS UNIDOS, 1995b, p. 21).

Mais revelador acerca do direcionamento da nova política de ajuda externa, o documento observa em tom de desaprovação que, nos últimos 10 anos, enquanto os recursos disponíveis para assistência externa se mantiveram constantes, o montante destinado aos programas de desenvolvimento aumentou significativamente em detrimento das iniciativas de ajuda militar aos aliados e parceiros nos assuntos de segurança dos Estados Unidos. 
Tabela 1: Comparação da alocação setorial do montante de recursos da ajuda externa

\begin{tabular}{|c|c|}
\hline \multicolumn{2}{|c|}{1984} \\
\hline Categoria & Percentual \\
\hline Militar & 43 \\
\hline Alimentação & 10 \\
\hline Desenvolvimento & 16 \\
\hline Multilateral & 9 \\
\hline Econômica & 18 \\
\hline Outra & 3 \\
\hline \multicolumn{2}{|c|}{1995} \\
\hline Categoria & Percentual \\
\hline Militar & 25 \\
\hline Alimentação & 9 \\
\hline Desenvolvimento & 22 \\
\hline Multilateral & 12 \\
\hline Econômica & 16 \\
\hline NIS/Eur & 8 \\
\hline Outra & 7 \\
\hline
\end{tabular}

Fonte: SENADO DOS ESTADOS UNIDOS, 1995b, p. 24.

No que diz respeito às medidas que atingem mais especificamente as atividades desenvolvidas pelo governo norte-americano na América Latina, o documento autoriza a apropriação de US\$105 milhões em ambos os Anos Fiscais de 1996 e 1997 para levar adiante os programas de controle internacional de narcóticos, reconhecendo explicitamente a importância dos países andinos e do México para que os esforços de controle do tráfico internacional de drogas sejam bem sucedidos: "Um programa continuado focado em iniciativas cooperativas com esses países é essencial para se implementar com sucesso [o controle] e, eventualmente, eliminar o tráfico ilegal de drogas" (SENADO DOS ESTADOS UNIDOS, 1995b, p. 32)

Em 1997, a Câmara iniciou o processo legislativo de uma complementação do Foreign Aid Reduction Act de 1995 conhecida como Foreign Affairs Reform and Restructuring Act de 1998. Embora aprovada em ambas as Casas, a proposta foi posteriormente vetada pelo presidente Clinton. Com propósitos semelhantes, o Foreign Affairs Reform and Restructuring Act de 1998, tinha por objetivo fortalecer a coordenação e a articulação entre as agências do executivo responsáveis pela formulação de política externa nos Estados Unidos e conferir ao Departamento de Estado autoridade máxima nesse processo. Consistente com seus objetivos, o documento reduziria a autonomia da USAID, o principal organismo do poder executivo de promoção de iniciativas voltadas ao desenvolvimento econômico, político e social dos países aos quais os Estados Unidos prestam ajuda externa, subjugando-o em última instância à Secretaria de Estado: 
Further, the bill requires that the Administrator of the AID serve under the direct authority of the Secretary of State and that the Secretary be given ultimate authority to coordinate U.S. development and economic assistance programs. (...) The bill also transfers into the Department of State certain functions of the Agency for International Development. (CÂMARA DOS DEPUTADOS DOS ESTADOS UNIDOS, 1998, p. 2 e 3)

A proposta de reorganizar as agências governamentais em prol de aumentar a eficiência da política externa norte-americana para atender aos desafios que se colocam no pós-Guerra Fria foi primeiramente uma iniciativa do próprio Congresso dois anos antes, em 1995. Em especial, a intenção de diminuir a autonomia de ação do USAID revela o descompasso entre as percepções da agência e do Congresso. De acordo com a versão anterior do documento, os programas da USAID não atendem aos interesses comerciais e de segurança nacional dos Estados Unidos e adotam como diretrizes centrais de suas ações as consideradas ineficientes políticas de assistência econômica e social (SENADO DOS ESTADOS UNIDOS, 1995b).

0 veto presidencial que frustrou essa tentativa de modificar a estrutura da administração governamental à época coincide com o ano em que se presencia o modelo de governo dividido. As eleições de 1994 foram uma grande derrota para o presidente Bill Clinton, que viu a maioria democrata do $104^{\circ}$ Congresso ser substituída pelo Partido Republicano. Essa situação gerou um cenário de confronto e paralisia decisória, retratada de forma bem evidente pela negativa do Congresso em renovar o mecanismo de fast-track, de natureza comercial, para dar continuidade às negociações de ampliação do NAFTA para países do Caribe (PASTOR, 1996), como desejava o presidente.

A partir do final do ano de 1996, o clima de tensão entre os dois poderes é amenizado. Cria-se maior convergência entre os discursos do presidente e dos representantes no Congresso, resultado da cooptação por parte do gabinete presidencial de diversos dos interesses expressos na arena legislativa (PASTOR, 1996).

A necessidade de estimular a articulação das agências na formulação de política externa resulta da percepção por parte do Congresso acerca da falta de sintonia entre os programas implementados e as políticas aprovadas, procurando criar mecanismos que possam conformar melhor as ações do executivo aos interesses dos legisladores:

Nonetheless, the Committee welcomes the recent support of the President to reform, revitalize and reorganize the United States' foreign affairs apparatus. Our nation's foreign affairs structures facilitate a ineffective dichotomy - which the nation cannot afford between programs and policy. (...) This reorganization seeks to make programs substantially more responsive to policy, ensuring that foreign affairs resources are expended wisely in support of the national interest (CÂMARA DOS DEPUTADOS DOS ESTADOS UNIDOS, 1998, p. 2 e 3$)$.

O Ato prevê a transferência, a partir de $1^{\circ}$ de outubro de 1998, das atividades de coordenação com relação à ajuda externa e das funções de relações públicas, imprensa e assuntos legislativos do USAID para o Departamento de Estado com o intuito de aproximar os interesses do Congresso sobre o direcionamento da política externa às políticas de assistência adotadas pelo executivo e à leitura que faz o Congresso das iniciativas dessa natureza. 
A prevista diminuição das atribuições exclusivas da USAID e a subordinação direta de seu representante à autoridade do Secretário de Estado reforçam o forte interesse do Congresso em restringir progressivamente os recursos destinados à ajuda externa nos moldes adotados pela USAID que dispensavam os Estados Unidos. Segundo o Comitê de Relações Exteriores: "Hoje, o Escritório Legislativo de Ajuda Externa e Assuntos Públicos conta com 52 funcionários e gastará US\$4.500,00 no Ano Fiscal de 1997. Sua transferência e reorganização para o Departamento de Estado servirá como um primeiro passo essencial para se iniciar renovada coordenação entre formulação de política externa e distribuição de ajuda externa". (Idem, p. 19).

Por fim, o Foreign Affairs Reform and Restructuring Act determina que os recursos direcionados para assistência econômica externa e desenvolvimento devam ser apropriados para o Secretário de Estado e não mais para o representante do USAID, confirmando o argumento anterior.

O Ato garante, no entanto, provisões para alguns programas específicos dessa natureza que acredita serem de extrema importância. Referentes ao hemisfério, o Radio Broadcasting for Cuba Act e o Television Braodcasting to Cuba Act recebem, para o Ano Fiscal de 1998 e 1999, a mesma quantia de US\$ 22.095 milhões. Ambas as iniciativas têm como objetivo disseminar informação na sociedade cubana, estimulando uma transição pacífica para o regime democrático.

As preocupações do Congresso com questões referentes aos direitos humanos e à estabilidade democrática nos países latino-americanos, contudo, permeiam recorrentemente os relatórios do Comitê de Relações Exteriores do Senado e do Subcomitê do Hemisfério Ocidental da Câmara. Embora, como já se argumentou, a própria questão hemisférica ocupe posição marginal na agenda do Congresso, os legisladores dispensam certa atenção à problemática da estabilidade dos regimes democráticos, apesar do crescente desinteresse dos representantes legislativos pela América Latina. Além de medidas legislativas, o Senado aprovou, entre 1997 e 1998, 20 resoluções direcionadas a países da região hemisférica. Oito das resoluções aprovadas expressam satisfação ou descontentamento frente à realização de eleições livres e democráticas nos países da região ${ }^{19}$, duas expressam preocupação com a situação dos direitos humanos em Cuba e as demais se referem a assuntos diversos não coincidentes entre si.

Durante o painel intitulado The U.S. and Latin America in the New Millenium: Outlook and Priorities, organizado pelo Subcomitê do Hemisfério Ocidental da Câmara, o deputado Robert Menendez, Democrata de New Jersey, demonstra que a estabilidade democrática surge como uma questão relevante enquanto alternativa para tratar as questões de segurança hemisférica, embora aparentemente seja mais problematizada na Câmara do que no Senado. A observação abaixo não questiona somente a ênfase no tratamento militar, mas também a priorização dos aspectos comerciais:

I mean can we with trade alone expect to control the illegal migration? Can we, with trade alone, seek to reduce the flow of illicit drugs? Can we, with trade alone, help consolidate fragile democracies? Can wem with trade alone, seek to reduce poverty, the spread of

19 Com relação ao Haiti, primeiramente o Senado incentiva a realização de eleições livres e democráticas e, posteriormente, nesse mesmo documento, condena a interrupção do processo (SENADO DOS ESTADOS UNIDOS, 1995a). 
infectious diseases or the environment? (...) Why can we not achieve a greater constituency to promote the necessary resources for the consolidation of that democracy? (CÂMARA DOS DEPUTADOS DOS ESTADOS UNIDOS, 2000a, p. 6).

Na mesma direção segue o argumento do deputado Republicano Cass Ballenger ao fazer o pronunciamento de abertura da audiência Guatemala and The Dominican Republic: Drug Corruption and Other Threat's to Democratic Stability para o Subcomitê do Hemisfério Ocidental, em outubro de 2002: "corrupção e instituições governamentais fracas continuam a impedir o controle do fluxo ilegal de narcóticos através da Republica Dominicana”. (CÂMARA DOS DEPUTADOS DOS ESTADOS UNIDOS, 2002a, p. 2)

Em termos de recursos, no entanto, a ajuda externa direcionada à estabilização e fortalecimento dos regimes democráticos no hemisfério foi bastante castigada ao longo dos anos. Em um período de 12 anos, os Estados Unidos reduziram a assistência bilateral para a região em dois terços, de US\$ 1.8 bilhões em 1995 para US\$ 600 milhões em 199720.

O compromisso do Congresso em autorizar a destinação de recursos para programas sociais nos países do hemisfério passa a enfrentar ainda outro obstáculo formal em decorrência da inclinação dos representantes em investir uma parcela cada vez maior do montante disponibilizado para a ajuda externa de natureza militar. Em 1996, o Congresso aprovou uma emenda ao Foreign Assistance Act of 1961 que requer do Departamento de Estado relatórios anuais que servem de base para a imposição de sanções a qualquer país que seja grande produtor de drogas ilícitas ou que sirva de trânsito para o tráfico de drogas. A administração deve emitir um certificado até $1^{\circ}$ de março de cada ano, atestando que os países, para que recebam assistência, tenham cooperado amplamente com os Estados Unidos no combate ao narcotráfico no ano precedente. As sanções a serem impostas aos países que não receberam certificação, de acordo com a seção 490 do Ato, referem-se à interrupção de assistência bilateral por parte do governo norte-americano e determinam que o Congresso vote contrariamente à liberação de empréstimos de bancos multilaterais de desenvolvimento para os países em questão (CÂMARA DOS DEPUTADOS DOS ESTADOS UNIDOS, 1997).

Esse novo modelo de paternalismo por meio de certificações reafirma a tendência do Congresso de afastar a política externa de programas considerados ineficientes na forma de lidar com os problemas de segurança. Esse comportamento pode ser identificado com mais precisão quando se observa que uma parcela cada vez maior dos recursos destinados à ajuda externa passa a ser direcionado para atender às políticas de viés militar no combate ao tráfico de drogas ilícitas.

A lógica do discurso no Congresso por parte daqueles que defendem a intensificação dos programas de vendas de equipamentos militares e parcerias entre as Forças Armadas para ações ofensivas sugere uma inversão do discurso característico da administração. No plano retórico, as agências governamentais apostam no fortalecimento da democracia como a forma mais eficaz de eliminar os problemas estruturais dos quais as ameaças de segurança transnacionais, como o tráfico de drogas, são reflexo. As armas são encaradas como instrumentos complementares

20 A USAID também reduziu consideravelmente o porcentual de programas desenvolvidos na região latino-americana: de $17 \%$ em 1988 para 7\% em 1999. (CÂMARA DOS DEPUTADOS DOS ESTADOS UNIDOS, 2000c). 
a iniciativas mais abrangentes no campo socioeconômico e político, demonstrando uma maior interdependência entre esses processos. Os congressistas adeptos da opção mais confrontativa, no entanto, parecem colocar a possibilidade de manutenção da democracia nos países da América do Sul em função da eficácia das investidas armadas.

Seguindo a mesma linha da ajuda externa, o problema da imigração irregular também passa a preocupar os tomadores de decisão norte-americanos com cada vez mais frequência nos anos 1990. A crise no Haiti em 1992 e a expectativa de que essa situação gerasse um grande fluxo de refugiados em direção ao território dos Estados Unidos motivou primeiramente Bush e, em seguida, Clinton a adotarem uma política vigilante de controle das fronteiras por meio da Guarda Costeira21(PASTOR, 1996; HYLAND, 1999; CAMERON, 2002).

Em 1996, o Congresso aprova uma nova lei de imigração cujos propósitos residiam em aumentar o controle sobre os fluxos de imigração, reduzir o número de refugiados aceitos legalmente no país e limitar o uso do sistema de bem-estar social e de outros benefícios governamentais para os imigrantes irregulares.

Apesar da visibilidade que o tema ganhou na primeira metade da década, dados sobre a opinião pública revelam que a imigração ilegal perde seu lugar de destaque dentre as preocupações de segurança da população especificamente com relação aos imigrantes de origem sul e centro-americana.

Tabelas 2 e 3: Pesquisa de opinião sobre imigração de latino-americanos para os Estados Unidos

\begin{tabular}{l|c|c|}
\hline \multicolumn{2}{|c|}{ Imigrantes Latinos vistos de maneira mais positiva } \\
\hline \multicolumn{1}{|c|}{$\begin{array}{c}\text { Amigrantes da } \\
\text { Amica Latina }\end{array}$} & $\begin{array}{c}\text { Abril } 1997 \\
\%\end{array}$ & $\begin{array}{c}\text { Maio } 2006 \\
\%\end{array}$ \\
\hline $\begin{array}{l}\text { Trabalham muito } \\
\text { Possuem fortes valores } \\
\text { familiares }\end{array}$ & 63 & 80 \\
\hline $\begin{array}{l}\text { Frequentemente dependem } \\
\text { do sistema de welfare }\end{array}$ & 55 & 80 \\
\hline $\begin{array}{l}\text { Aumentam a criminalidade } \\
\text { significativamente }\end{array}$ & 43 & 33 \\
\hline
\end{tabular}

\begin{tabular}{|l|c|c|c|}
\hline \multicolumn{4}{|c|}{ Crescente preocupação com questões de imigração } \\
\hline \multicolumn{1}{|c|}{ Os imigrantes hoje } & $\begin{array}{c}\text { Set } 2000 \\
\%\end{array}$ & $\begin{array}{c}\text { Dez } 2005 \\
\%\end{array}$ & $\begin{array}{c}\text { Março 2006 } \\
\%\end{array}$ \\
\hline $\begin{array}{l}\text { São um peso, pois pegam } \\
\text { empregos, moradia }\end{array}$ & 38 & 44 & 52 \\
\hline $\begin{array}{l}\text { Fortalecem os EUA com } \\
\text { seu trabalho e talento }\end{array}$ & 50 & 45 & 41 \\
\hline Não sabe & 12 & 11 & 7 \\
\hline
\end{tabular}

Fonte: Pew Research Center for the People \& the Press e Pew Hispanic Center, 2006, p. 1

Da mesma maneira, talvez como reflexo desse quadro, o problema da imigração foi marginalizado pelo Congresso nos anos subsequentes. Sua visibilidade nos comitês foi significativamente reduzida, sobretudo em comparação à questão do tráfico de drogas e mesmo da preocupação com a estabilidade democrática. Uma observação interessante é que nas audiências organizadas pelos subcomitês para assuntos hemisféricos, os congressistas não

21 A política de enviar os refugiados novamente para o seu país de origem foi inicialmente criticada por Clinton que, após assumir a presidência, adotou a mesma postura. 
abordam o problema da imigração pela ótica do tráfico, ou vice-versa, tal com acontece com a questão democrática22.

A provisão de recursos também não sofreu alterações. Para o ano fiscal de 1998 e 1999, o Congresso estipulou uma quantia de US\$650 milhões para assistência a refugiados e questões de imigração e mais US\$50 milhões para emergências da mesma natureza. Esse número se manteve estável em comparação a 1996 e 1997 (CÂMARA DOS DEPUTADOS DOS ESTADOS UNIDOS, 1998).

\section{Um caso a parte: o tráfico ilegal de drogas}

O caso do tráfico ilegal de narcóticos dominou a agenda hemisférica de segurança no pósGuerra Fria e foi a grande preocupação dos tomadores de decisão na década de 1990. Apesar disso, o Congresso continua a dar pouco destaque ao hemisfério na sua agenda, e a questão do tráfico enquanto tema de política externa não é exceção ${ }^{23}$. Das questões de segurança hemisférica que se colocavam, no entanto, o tráfico foi certamente o que mais mobilizou os comitês específicos da Câmara e do Senado.

Os diversos painéis de discussão organizados pelos subcomitês para assuntos hemisféricos das duas Casas dedicados a diagnosticar a situação nos países andinos, em especial Colômbia e Bolívia, e as repercussões desse processo na esfera doméstica revelam a priorização da temática pelos formuladores de política24.

Nem o problema, nem o comportamento do governo norte-americano nos anos em questão são inéditos. Os Estados Unidos, desde a administração Reagan (1980-1988), atribuíram ao tráfico de drogas lugar privilegiado na agenda de segurança hemisférica, declarando-o uma ameaça à segurança nacional, permanecendo dessa forma designado desde então (Youngers e Rosin, 2005). O combate à tal ameaça "deveria vir de um ataque in locus contundente à oferta da droga, quer dizer, atacar a produção na sua fonte em países como Bolívia, Colômbia, Equador e Peru" (Villa, 2005, p. 6), além de interceptar seu transporte (Youngers e Rosin, 2005). A guerra às drogas (war on drugs), expressão já incorporada ao vocabulário dos decisores norte-americanos, é intensificada na segunda metade da década de 1980. A elevação da questão ao patamar da Segurança Nacional autoriza os tomadores de decisão a lançar mão de qualquer recurso disponível para a solução do problema, permitindo sua militarização (Villa, 2005, Youngers e Rosin, 2005)25. 0 processo de militarização consistiu, resumidamente,

22 Vale ressaltar também que não houve nenhuma audiência específica sobre imigrações no período.

23 Entre os anos de 1994-1999, dentre os assuntos de segurança, o Congresso se pronuncia com mais recorrência sobre a reforma das Nações Unidas, o tema da não proliferação nuclear, as questões envolvidas na expansão da Organização do Tratado do Atlântico Norte (OTAN) para os países do Leste Europeu e posiciona-se com relação à Rússia e à China.

24 Entre janeiro de 1997 e outubro de 1998, o Subcomitê para Assuntos do Hemisfério Ocidental e do Corpo da Paz do Senado realizou somente três painéis de debate, todos eles relacionados ao problema das drogas: Mexican and American Responses to the International Narcotics Threat (12/3/1997), Drug Cartels \& Narco-Violence: Threat to the U.S. (16/7/1997) e Drug Trafficking \& Certification (26/2/1998). (SENADO DOS ESTADOS UNIDOS, 1999).

25 Um movimento institucional revelador desse processo de militarização do problema do tráfico de drogas foi a transferência para o Departamento de Defesa da responsabilidade de monitorar e detectar o transporte de drogas ilícitas para os Estados Unidos (Youngers e Rosin, 2005). 
"na expansão do papel das Forças Armadas tanto na América Latina quanto nos Estados Unidos nas iniciativas de combate às drogas, ao treinamento de forças policiais civis em estratégias e operações militares, e a tendência à assistência militar e policial ter precedência sobre [a assistência voltada] para objetivos de natureza socioeconômicos ou instituições democráticas" (YOUNGERS e ROSIN, 2005, p. 3).

Assim se manteve também a percepção e os investimentos do problema nos anos subsequentes. O governo Clinton reteve basicamente todos os elementos do seu predecessor no cargo, embora tenha colocado menos ênfase na interdição e mais na erradicação e no desmantelamento de cartéis. A tendência à militarização, embora suavizada pelo cuidado também com o outro lado da equação, ou seja, a parte da demanda, continuou crescente. Os gastos com a guerra às drogas alcançaram a cifra de US\$ 70 bilhões desde que o presidente Bush a declarou no início dos anos 1990 (PASTOR, 1996). Essa escalada no processo de militarização culminou com a aprovação do Congresso, no ano 2000, do Plano Colômbia.

Apesar da convergência de percepções identificada na década de 1990 entre os demais países da região e os Estados Unidos acerca da relevância do tráfico de drogas enquanto ameaça à segurança nas Américas, seja em decorrência da incapacidade da região articular autonomamente sua agenda, seja pela incorporação impositiva da agenda norte-americana, o fato é que essa situação não foi aproveitada como oportunidade para moldar políticas com tons cooperativistas por parte do Congresso.

Curiosamente, no entanto, em 1997, a Foreign Affairs Reform and Restructuring Act aprovado pelo Congresso reconhece o caráter intrinsecamente transnacional do problema e explicita sua crença na necessidade de se criar com urgência algum tipo de acordo cooperativo com os países da região para que se obtenham resultados mais satisfatórios na luta contra o narcotráfico. Se, por um lado, o interesse no multilateralismo coloca-se como uma abordagem original na relação entre os Estados Unidos e os demais países hemisféricos para a resolução do problema, por outro, o conteúdo final das políticas a serem adotadas por uma aliança ou qualquer outro arranjo multilateral não sofrem mudanças significativas. Os meios a serem adotados continuam pautando-se em estratégias de curto prazo e de alcance limitado em termos de permeabilidade das estruturas política, econômica e social nas quais se apóiam o tráfico:

\footnotetext{
"The committee finds that efforts to counter drug trafficking in the Western Hemisphere have been hampered by policies that approach this transnational problem as a series of bilateral relationships. This dynamic has created the impression that antidrug policy is a struggle between the governments of the United States and our hemispheric neighbors, rather than a common battle against the narcotics mafias. (...) Such an alliance would seek to launch collective strategies incorporating firm goals and timetables to address the production, transport, and consumption of illegal drugs" (CÂMARA DOS DEPUTADOS DOS ESTADOS UNIDOS, 1998, p. 42)
}

A dificuldade de se organizar arranjos cooperativos pode ser resultado de leituras diferenciadas sobre as alternativas para neutralizar a ameaça. É preciso reconhecer que as percepções de ameaça identificadas pelos Estados Unidos e seus vizinhos ao sul, embora 
coincidam em termos de conteúdo, ganham ênfases diferenciadas sobre meios e estratégias de alcançar os resultados desejados, dificultando a coordenação de ações estratégicas. A leitura acerca dos fenômenos causadores de insegurança no continente recebe atenção especial dos Estados Unidos à medida que transparecem enquanto ameaça à sua própria sociedade. Em outras palavras, são ameaças à sua estabilidade social doméstica oriundas da região sul e centro-americanas. Como esses processos impactam de forma imediata nos países da América do Sul, Central e do Caribe, suas preocupações, em geral, não estão sujeitas diretamente a soluções militares, mas sim requerem investimentos de longo prazo no desenvolvimento e na consolidação das instituições democráticas e alteração de estruturas econômicas. (HAYES, 2007).

A aprovação do Plano Colômbia pela vasta maioria dos membros do Congresso não deixa muitas dúvidas quanto ao reconhecimento dos méritos de uma abordagem militarizada ao tráfico de substâncias ilícitas ${ }^{26}$. Em uma deliberação do Congresso acerca do problema dos narcóticos ilegais nas Américas, o deputado republicano da Flórida John Mica faz a seguinte afirmação:

\footnotetext{
"The Clinton administration closed down any semblance of a war on drugs. In hearings that we have held, even today, we found that the $\$ 300$ million that this Congress appropriated for Colombia some 2 years ago, getting the resources to Colombia, were in fact bungled. We find even in a \$ 1 billion education program we are paying 179 percent over industry standards for placement of ads, and instead of paying a 3,5 percent industry average commission, we are paying 14 percent plus, so ads are not going on the public education and information media. An anti-narcotics campaign is not what the Congress intended" (CÂMARA DOS DEPUTADOS DOS ESTADOS UNIDOS, 2000g, p. 22434).
}

O Plano Colômbia se beneficiou de uma medida emergencial aprovada pelo Congresso em agosto de 2000 e autorizava a liberação de US\$1,3 bilhões suplementares para o fortalecimento das atividades de combate à produção do tráfico de drogas na América Latina, sendo que, dessa verba, US\$ 1.018 bilhões deveriam ser alocados especificamente para o programa.

Embora a colocação do representante Mica transcrita acima assuma um tom de crítica um pouco extremado em comparação aos demais membros do Congresso, tanto nos debates internos dos comitês e subcomitês quanto no plenário, o Plano Colômbia suscitou alguma divergência em relação à distribuição dos recursos por parte da administração e pelo próprio conteúdo do programa.

Representantes como o republicano de Indiana Dan Burton e o democrata de Nova York Gary Ackerman questionavam, durante audiência promovida pelo Subcomitê do Hemisfério Ocidental da Câmara, o consumo de parcela significativa dos 75\% dos recursos destinados à compra de equipamentos e pulverizações do Plano por parte das Forças Armadas Colombianas. A desconsideração de critérios pautados no histórico de violação dos direitos humanos da

26 Arturo Valenzuela, no entanto, Assistente Secretário Especial do Presidente Clinton e Diretor Sênior para Assuntos Interamericanos do Conselho de Segurança Nacional na Casa Branca no segundo governo Clinton, um dos articuladores do Plano Colômbia, afirma, em entrevista concedida à autora em fevereiro de 2009, que a percepção militarizada com base em alocação de recursos do Plano não se justifica uma vez que o uso de contingentes e equipamentos militares produzem gastos mais elevados em si. Proporcionalmente, portanto, o montante alocado para essa dimensão das atividades seria necessariamente mais significativa. 
instituição militar da Colômbia para a alocação dos recursos, em contraposição aos altos índices atribuídos à Polícia Nacional Colombiana, é o elemento que causa desconforto nessa situação. Nas palavras de Ackerman:

"The second point we must consider is who we are providing assistance to. The Colombian National Police have and outstanding human rights record. They are an organization we should be proud to assist. The bulk of Plan Colombia and its assistance will go to the Colombian military, which has one of the worst human rights records in the hemisphere. On top pf that, there are critical allegations of ongoing cooperation between elements of the Colombian military and paramilitary organizations" (CÂMARA DOS DEPUTADOS DOS ESTADOS UNIDOS, 2000e, p. 4)

Contudo, os congressistas não desconsideram unanimemente a necessidade de complementar a iniciativa da guerra às drogas com uma estratégia que busque enfraquecer a demanda pelo produto. O próprio Ackerman explicita esse aspecto27:

"In a very real sense, much of the turmoil in Colombia is our fault. Our citizens consume the drugs, grown and produced in Colombia. Yet, at the policy-making level, we don't spend much time talking about demand reduction. For me, this is basic economics, demand drives supply, and unless we intensify our efforts to reduce demand here, a supply side strategy is doomed to fail". (CÂMARA DOS DEPUTADOS DOS ESTADOS UNIDOS, 2000e, p. 5)

A crítica de alguns congressistas acerca do limite estreito das iniciativas da administração no plano doméstico também reverbera na sua percepção acerca da sua atuação no plano hemisférico. 0 posicionamento dos congressistas acerca do papel dos Estados Unidos na implementação do Plano Colômbia demonstra como o uso da força enquanto instrumento privilegiado da estratégia norte-americana apresenta-se como insuficiente:

\begin{abstract}
"While the 2-year, \$1.3 billion aid package, and we recently approved, incresead assistance for economic development and democracy building programs in Colombia, it also directs the lion's share of the aid about 75 percent for counternarcotics programs. Frankly, I wish the aid package was a little bit more balanced with more aid targeted toward democratization and economic development programs. I believe the real path to peace in Colombia resides in two places, in the hearts of the Colombian people and the resolve of the United States to help Colombia in its efforts to fight narco-traffickers and to institute broad economic and civic reforms" (CÂMARA DOS DEPUTADOS DOS ESTADOS UNIDOS, 2000e, p. 21)
\end{abstract}

Diversos representantes eleitos para o Congresso, em oportunidades diferentes, relataram concordar com o Plano Colômbia como uma iniciativa que se justificava pela premência de se tratar o assunto do tráfico de drogas a despeito de suas discordâncias com relação ao foco central do projeto. Os críticos do pacote final aprovado pelo Congresso acreditavam na

27 Embora a predominância nos pronunciamentos dos representantes seja a crítica em relação à marginalização das políticas voltadas para a demanda, esse posicionamento não é unânime. O senador Republicano da Flórida John Mica acredita que o esquema de cooperação na troca de informações com os parceiros latino-americanos e o aparato institucional do poder executivo foi paulatinamente desarticulado pela administração Clinton, cuja mudança de foco da guerra às drogas para políticas de contenção da demanda doméstica se mostraram extremamente ineficientes. 
necessidade de os Estados Unidos instituírem políticas mais assertivas para ajudar a Colômbia e a região Andina, de forma geral, a lidar com o problema da produção de drogas, discordavam da forma com que a alocação de recursos fora partilhada entre os programas previstos pela administração, aprovada como lei.

A preocupação com as repercussões da ação militarizada para a estabilidade política dos países vizinhos à Colômbia também permeia as observações dos congressistas. Logo após o programa entrar em vigor, uma pequena cidade no Panamá foi atacada por membros de uma unidade paramilitar colombiana. Afirmam documentos do Congresso que a intensificação do conflito doméstico em território colombiano pressiona a escalada da militarização das fronteiras do país com o Brasil e a Venezuela, onde autoridades colombianas reclamam acerca de incursões de forças venezuelanas em seu território buscando erradicar plantações de ilícitos na divisa de seus territórios. O Brasil também protesta quanto a avanços esporádicos de fronteira por parte das forças colombianas e de unidades das FARC. O fluxo de refugiados colombianos em direção ao Equador em decorrência da intensificação da política de guerra às drogas também aparece como uma consequência indesejável e geradora de instabilidades das ações norte-americanas na região (SENADO DOS ESTADOS UNIDOS, 2000c; CÂMARA DOS DEPUTADOS DOS ESTADOS UNIDOS, 2000e).

O caráter transnacional que assume a ameaça colocada pelo tráfico de drogas, transformando-a em um problema de segurança doméstica e internacional, tal como percebido pelos formuladores de política externa norte-americana, permite que os congressistas esperem maior cooperação da comunidade internacional para lidar com a situação nos países Andinos. O senador Democrata Christopher Dodd, de Connecticut, faz a seguinte observação, em novembro de 2000:

"Additional judicial and military reforms must be implemented in order for the rule of law to become the norm and military impunity to cease once and for all. Economic investments, especially in alternative development programs, must be forthcoming if peasants who currently depend on coca cultivation to feed their families are to have meaningful alternative employment. All of these areas are well within the financial resources and expertise of our European allies to undertake, if they are truly concerned about the future of Colombia. (...) A bipartisan congress signed up to that position when it voted to appropriate the $\$ 1.3$ billion in emergency assistance. Having said that, I do not believe Plan Colombia can ultimately be successful implemented if only the U.S. and Colombian Governments are participants." (SENADO DOS ESTADOS UNIDOS, 2000c, p. 6 e 7)

Robert Menendez, representante do Partido Democrata na Câmara acredita, no entanto, que a falta de interesse dos parceiros europeus em contribuir para o combate ao tráfico de drogas se deve exatamente à leitura de que a abordagem norte-americana peca em estabelecer objetivos de natureza política e econômica mais adequados para resolver o problema na sua essência.

Após os atentados terroristas de 11 de setembro de 2001, o perfil das políticas de combate ao narcotráfico se manteve inalterado no que diz respeito à tendência da militarização da abordagem. A criação da Iniciativa Regional Andina, em 2001, ampliou o escopo de países a 
serem beneficiados com recursos norte-americanos para o combate antidrogas. Rebatizado posteriormente de Iniciativa Andina Antidrogas, o programa "teve um orçamento aprovado pelo Congresso dos EUA em 2003 de 700 milhões de dólares, e para 2004 de 731 milhões de dólares. No entanto, nos dois orçamentos, a prioridade dada à Colômbia é evidente: 63\% do orçamento é destinado aos programas de erradicação e pulverização da droga em larga escala, assim como para o treinamento e compra de equipamentos militares, repartindo-se o restante dos 731 milhões entre o Peru, a Bolívia e o Equador, nessa ordem" (Villa, 2006, p. 17).

No entanto, o narcotráfico na América Latina passa a ser considerada uma atividade terrorista, vocabulário inédito para se referir ao fenômeno na região hemisférica28. A leitura dos congressistas encara o tráfico de drogas e as redes terroristas, a partir de então, como entidades que se encontram em simbiose, se fortalecendo mutuamente. Cass Ballenger faz a seguinte observação:

"Colombia's two largest insurgencies, the Revolucionary Armed Forces of Colombia, or FARC, and the National Liberation Army, or ELN have been listed by the U.S. Department of State as both drug traffickers and terrorist organizations. (...) The involvement of well known international terrorists as the IRA, combined with the recent threats made by FARC's leader, (...) suggesting that he will hit American targets in response to our nation's support of the drug war, raises real questions about the FARC's role in the support of international terrorism" (CÂMARA DOS DEPUTADOS DOS ESTADOS UNIDOS, 2001, p. 2)

\section{Considerações finais}

Esse artigo tinha por objetivo apresentar de que maneira as principais questões que compõem a agenda de segurança hemisférica são tratadas pelo Congresso norte-americano. Tal esforço pretende contribuir para responder a uma indagação: o que explicaria a dissonância entre o discurso dos formuladores de política externa americana, fortemente sustentado na interconexão entre comércio, estabilidade democrática e as ameaças de segurança no hemisfério, e suas iniciativas na região, marcadas por forte teor militar?

A compreensão do processo de formulação da agenda de segurança hemisférica parece ser um caminho promissor para se buscar uma resposta. Levando em consideração que os estudos de definição de agenda procuram, por um lado, descobrir porque determinados temas ganham distinção em detrimento de outros e, por outro lado, quem são os atores que protagonizam as lutas políticas por trás desse processo, o artigo procurou mostrar quais foram os termos e os temas levantados pelas discussões no Congresso - um dos atores dessa arena no que tange à agenda de segurança hemisférica, nos anos 1990 e início dos anos 2000.

A avaliação dos principais temas da agenda de segurança para a região aponta que existia de fato no Congresso considerável permeabilidade da leitura que favorecia a abordagem militar como a forma mais adequada para lidar com as ameaças de segurança na região sul e

28 Embora o Departamento de Estado tenha considerado o grupo paramilitar AUC como terrorista poucos dias antes dos atentados, somente depois de setembro de 2001 é possivel identificar nos documentos do Congresso referências de seus representantes associando a expressão ao conflito colombiano. 
centro-americana, em particular com o tráfico de drogas. No entanto, um grupo minoritário de congressistas, aparentemente com maior representação no Partido Democrata e na Câmara, se contrapunha a essa interpretação, expressando preferência por estratégias mais diversificadas para lidar com tais problemas. Temáticas associadas, como democracia, direitos humanos e imigração irregular aparecem no discurso de ambos os grupos, assumindo significados similares, embora para o primeiro grupo, dominante na definição da agenda hemisférica, essas temáticas fossem colocadas em função da agenda militarizada do tráfico de drogas.

Fatores distintos podem ser aventados para explicar essa tendência à militarização, embora com alguma dissonância. Por um lado, o recurso aos meios militares aparece como uma alternativa eficaz para prestação de contas. Consiste em iniciativas direcionadas, de mais fácil mensuração e com impacto de curto prazo, em contraposição, por exemplo, ao investimento em educação ou reforma das instituições políticas, cuja relação de causa-efeito é mais difusa, mais complexa e qualquer avaliação apropriada sobre seus impactos mais abrangentes sobre fenômenos como tráfico de drogas ou imigração ocorrem no médio/longo prazo. Em decorrência das características do sistema político norte-americano, outro elemento que parece central para compreender as escolhas políticas desses atores reside na composição da base eleitoral dos membros do Congresso envolvidos com as questões hemisféricas. Matizes ideológicos, interesses econômicos, religiosos ou clivagens sociais de outra natureza potencialmente influenciam no posicionamento dos congressistas. Vale lembrar que as questões hemisféricas ocupam posição marginal na agenda de política externa dos EUA, com alguma variação pouco significativa nesse período, um fator que precisa ser equacionado em qualquer análise. Também é possivel pensar que a pouca visibilidade da agenda permita que seus temas funcionem como elementos de barganha entre o Poder Executivo e o Legislativo, deixando prevalecer as preferências dos primeiros na determinação das políticas.

\section{Referências Bibliográficas:}

ALLISON, Graham T e ZELIKOW, P. 1999. Essence of a Decision. New York, Longman.

BICKERS, Kenneth N., STEIN, Robert. 2000. The Congressional Pork Barrel in a Republican Era. The Journal of Politics, Vol. 62, n. 4.

CÂMARA DOS DEPUTADOS DOS ESTADOS UNIDOS. 1997. Disapproval of Determination of President Regarding México. Relatório 105-10. 105 Congresso. Primeira Sessão. Washington: U.S. Government Printing Office.

CÂMARA DOS DEPUTADOS DOS ESTADOS UNIDOS. 1998. Foreign Affairs Reform and Restructuring Act of 1998. Projeto de Lei H.R.1757 [Relatório Nº 106-28]. 106 Congresso. Primeira Sessão. Washington; U.S. Government Printing Office.

CÂMARA DOS DEPUTADOS DOS ESTADOS UNIDOS. 2000a. The U.S. and Latin America in the New Millennium: Outlook and Priorities. Audiência do Subcomitê para o Hemisfério Ocidental do Comitê de Relações Internacionais - $106^{\circ}$ Congresso. Segunda Sessão. Número de Série 106-104. Washington; U.S. Government Printing Office. 
CÂMARA DOS DEPUTADOS DOS ESTADOS UNIDOS. 2000b. The Challenges to Hemispheric Democracy: Elections, Coups and Instability. Audiência do Subcomitê para o Hemisfério Ocidental do Comitê de Relações Internacionais $-106^{\circ}$ Congresso. Segunda Sessão. Número de Série 106-127. Washington; U.S. Government Printing Office.

CÂMARA DOS DEPUTADOS DOS ESTADOS UNIDOS. 2000c. Development, Growth, and Poverty Reduction in Latin America: Assessing the Effectiveness of Assistance. Audiência do Subcomitê para o Hemisfério Ocidental do Comitê de Relações Internacionais - $106^{\circ}$ Congresso. Segunda Sessão. Número de Série 106-129. Washington; U.S. Government Printing Office.

CÂMARA DOS DEPUTADOS DOS ESTADOS UNIDOS. 2000d. Security Assistance Act of 2000. Lei H.R.4919 [Relatório N 106-351]. 106 Congresso. Segunda Sessão. Washington: U.S. Government Printing Office.

CÂMARA DOS DEPUTADOS DOS ESTADOS UNIDOS. 2000e. Implementing Plan Colombia: the U.S. Role. Audiência do Subcomitê para o Hemisfério Ocidental do Comitê de Relações Internacionais - $106^{\circ}$ Congresso. Segunda Sessão. Número de Série 106-188. Washington; U.S. Government Printing Office.

CÂMARA DOS DEPUTADOS DOS ESTADOS UNIDOS. 2000f. Threats to Our National Sovereignty. Congressional Record. H8195-H8197. Washington: U.S. Government Printing Office.

CÂMARA DOS DEPUTADOS DOS ESTADOS UNIDOS. 2000g. The Problem of Illegal Narcotics in America. Congressional Record, V. 146, Pt. 15. 22434. Washington: U.S. Government Printing Office.

CÂMARA DOS DEPUTADOS DOS ESTADOS UNIDOS. 2001. The Western Hemisphere's Response to the September 11, 2001 Terrorist Attack on the United States. Audiência do Subcomitê para o Hemisfério Ocidental do Comitê de Relações Internacionais - $107^{\circ}$ Congresso. Primeira Sessão. Número de Sério 107-43. Washington; U.S. Government Printing Office.

CÂMARA DOS DEPUTADOS DOS ESTADOS UNIDOS. 2002a. Guatemala and Dominican Republic: Drug, Corruption and Other Threats to Democratic Stability. Audiência do Subcomitê para o Hemisfério Ocidental do Comitê de Relações Internacionais - $107^{\circ}$ Congresso. Segunda Sessão. Número de Série 107-118. Washington; U.S. Government Printing Office.

CÂMARA DOS DEPUTADOS DOS ESTADOS UNIDOS. 2002b. Update on Efforts to Bring about Democratic Reform in Cuba; and Halting of Northern Ireland Assembly. Congressional Record. H8018-H8019. Washington: U.S. Government Printing Office.

CAMERON, Frasier. 2002. US Foreign Policy After the Cold War. Global Hegemon or Reluctant Sherif? New York: Routledge.

CLARKE, M. and WHITE, B. (eds.) 1995. Understanding foreign policy. The foreign policy systems approach. Brookfield: Ashgate Publishing Company.

DEIBEL, Terry L. 2000. Clinton and Congress. The Politics of Foreign Policy. New York: Foreign Policy Association.

HAHN, April Diane. 2003. Congress, Domestic Value and U.S. Policy for Latin America and Caribbean. Tese de doutorado apresentada na University of Virginia.

HARDY, Alfredo. 1995. O Processo Decisório na Política Externa Norte-Americana. Política Externa, Vol. 4, n. 1, p. 87-99. 
HAYES, Margareth D. 2007. "Partner's of Choice? Prospects for Cooperation on the Multidimensional Security Agenda". 20 março 2007. Meeting to review progress in implementing the Declaration on Security in the Americas.

HERZ, Monica. 2002. Política de Segurança dos Estados Unidos para a America Latina após a Guerra Fria. Estudos Avançados, Vol. 16, n. 46 São Paulo (Sept./Dec.)

HYLAND, William G. 1999. Clinton’s World. Remaking American Foreign Policy. Westport: Greenwood Publishing Group.

KEGLEY, Charles, Jr., WITTKOPF, Eugene R. 1996. American Foreign Policy. Pattern and Process. St. Martin's Press: New York.

KINGDOM, John W. 1995. Agendas, Alternatives and Public Policies. New York, NY: Longman.

LINDSAY, James M., RIPLEY, Randall B. 1992. Foreign and Defense Policy in Congress: a research agenda for 1990's. Legislative Studies Quarterly, Vol. 17, n. 3.

LOHMANN, Susanne, O'HALLORAN, Sharyn. 1994. Divided Government and US Trade Policy: Theory and Evidence. International Organization, vol 48, n. 4, p. 595 - 632.

MARTIN, Lisa. 2001. Democratic commitments: legislatures and international cooperation. New Jersey: Princeton University Press.

MILNER, Helen. 1997. Interest, Institutions and Information: Domestic Politics and International Relations. Princeton: Princeton University Press,

PASTOR, Robert. 1996. The Clinton Administration and the Americas: the postwar rhythm and blues. Journal of Interamerican Studies and World Affairs. Vol. 38, n. 4.

PEW RESEARCH CENTER FOR THE PEOPLE \& THE PRESS, PEW HISPANIC CENTER. No Consensus on Immigration Problem or Proposed Fixes. America's Immigration Quandary. 30 de março de 2006. Disponivel em http://www.people-press.org/files/legacy-pdf/274.pdf - acesso em 16 de maio de 2015.

SENADO DOS ESTADOS UNIDOS. 1995a. Legislative Activities Report of the Committee on Foreign Relations. Relatório 104-21. $104^{\circ}$ Congresso. Primeira Sessão. Washington: U.S. Government Printing Office.

SENADO DOS ESTADOS UNIDOS. 1995b. Foreign Aid Reduction Act of 1995. Relatório 104-99. $104^{\circ}$ Congresso. Primeira Sessão. Washington: U.S. Government Printing Office.

SENADO DOS ESTADOS UNIDOS. 1996. Immigration Control and Financial Responsibility Act of 1996. Relatório 104-249. 104 Congresso. Segunda Sessão. Washington: U.S. Government Printing Office.

SENADO DOS ESTADOS UNIDOS. 1998. Security Assistance Act of 1998. Lei S.2463 [Relatório N 105-333]. Calendário N $576.105^{\circ}$ Congresso. Segunda Sessão. Washington: U.S. Government Printing Office.

SENADO DOS ESTADOS UNIDOS. 1999. Legislative Activities Report of the Committee on Foreign Relations. Relatório 106-35. 106 Congresso. Primeira Sessão. Washington: U.S. Government Printing Office.

SENADO DOS ESTADOS UNIDOS. 2000a. Supporting Efforts of Bolivia's Democratically Ellected Government. Congressional Record. 23497. Washington: U.S. Government Printing Office. 
SENADO DOS ESTADOS UNIDOS. 2000b. Senate Concurrent Resolution 155 - Expressing the Sense of Congress that the Government of the United States Should Activelly Suppot the Aspirations of the Democratic Political Forces in Peru toward an Immediate and Full Restoration of Democracy in that Country. Congressional Record. 23903. Washington: U.S. Government Printing Office.

SENADO DOS ESTADOS UNIDOS. 2000c. Events in Colombia. Congressional Record. 25816-25818. Washington: U.S. Government Printing Office.

SENADO DOS ESTADOS UNIDOS. 2000d. Legislative Activities Report of the Committee on Foreign Relations. Relatório 107-9. $107^{\circ}$ Congresso. Primeira Sessão. Washington: U.S. Government Printing Office.

SENADO DOS ESTADOS UNIDOS. 2002. Security Assistance Act of 2001. Ato S.1803. $107^{\circ}$ Congresso. Segunda Sessão. Washington: U.S. Government Printing Office.

VILLA, Rafael Duarte. 2005. Os Países Andinos: Tensões entre Realidades Domésticas e Exigências Externas. In: Dupas, Gilberto (coord.). América Latina no início do século XXI. Perspectivas econômicas, sociais e políticas. Rio de Janeiro/São Paulo: Fundação Editora da Unesp/Instituto de Estudos Econômicos e Internacionais.

VILLA, Rafael Duarte. 2006. Política Externa de Segurança dos Estados Unidos para a América do Sul: Significados e Impactos dos fatores domésticos. Artigo apresentado para o $5^{\circ}$ Encontro da Associação Brasileira de Ciência Política. Belo Horizonte (27 a 29 Julho)

WIARDA, Howard J. 1997. Consensus Found, Consensus Lost: Disjuctures in U.S.Policy toward Latin America at the Turn of the Century. Journal of Interamerican Studies and World Affairs, Vol. 39, n. 1, Special Issue:US - Latin American Relations.

WITTKOPF, Eugene R., McCORMICK, James M. 1998. The Congress, the President, and the End of the Cold War: has anything changed? The Journal of the Conflict Resolution, Vol. 42, n. 4.

YOUNGERS, Coletta A., ROSIN, Eileen. 2005. The U.S. "War on Drugs": Its Impact in Latin America and the Caribbean. In: YOUNGERS, Coletta A., ROSIN, Eileen (eds). Drugs and Democracy in Latin America. The impact of U.S. Policy. Boulder, Colorado: Lynne Rienner Publishers, Inc.

Recebido em: 31 maio 2015 Aceito em: 15 outubro 2015 